\title{
Trotz Krankenschein ins Café?
}

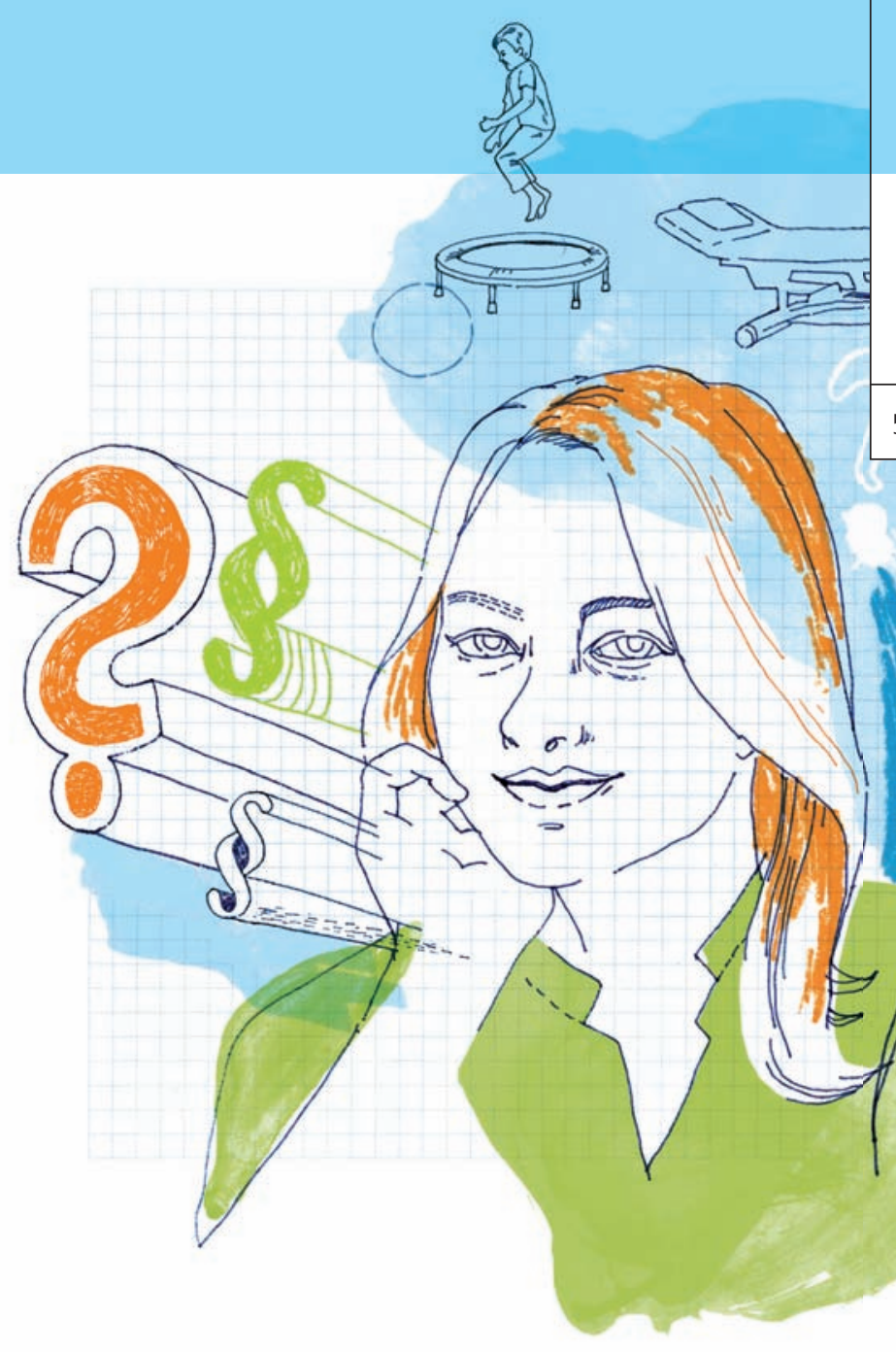

\section{Die Antwort unseres Experten}

Grundsätzlich ja. Hintergrund der Frage ist natürlich, ob der Arbeitnehmer seinen Anspruch auf Entgeltfortzahlung verliert oder sogar sein Arbeitsverhältnis riskiert, wenn er trotz Krankschreibung ein Café besucht. Prinzipiell verpflichtet er sich dazu, seine Arbeitskraft zur Verfügung zu stellen, der Arbeitgeber zahlt die vereinbarte Vergütung. Ist der Arbeitnehmer arbeitsunfähig und kann seinen Verpflichtungen nicht mehr nachkommen, behält er laut Entgeltfortzahlungsgesetz seinen Entgeltanspruch.

Laut Arbeitsunfähigkeitsrichtlinien gilt man als arbeitsunfähig, wenn man seine Tätigkeit aufgrund von Krankheit nicht mehr oder nur unter der Gefahr der Krankheitsverschlimmerung ausführen kann. Um die Arbeitsunfähigkeit beurteilen zu können, muss ein Arzt den Versicherten zur Tätigkeit und den damit verbundenen Anforderungen und Belastungen befragen. Kann ein Arbeitnehmer seine Tätigkeit nicht mehr ausführen, heißt das nicht automatisch, dass er auch am gesellschaftlichen Leben nicht mehr teilnehmen kann.
Er darf also, wenn es sein Gesundheitszustand erlaubt, durchaus ein Café aufsuchen, ins Theater oder ins Kino gehen. Selbstverständlich sind auch Spaziergänge möglich. Ein Patient sollte aber den Arzt vorher danach fragen, um auszuschließen, dass der beabsichtigte Theaterbesuch oder der Spaziergang die Genesung verzögert.

Im Arbeitsverhältnis hat die vom Arzt ausgestellte Arbeitsunfähigkeitsbescheinigung einen Beweiswert. Diesen kann der Arbeitgeber nur dann erschüttern, wenn er von Tatsachen weiß, die ihn ernsthaft an der bescheinigten Arbeitsunfähigkeit zweifeln lassen. Zum Beispiel, wenn die Freizeitaktivität des Arbeitnehmers mit der Arbeitsunfähigkeit unvereinbar ist. Bloße Besorgungs- oder Einkaufsgänge würden nicht dazuzählen. Auch ein Café-Besuch ist in der Regel vereinbar. Sieht ein Arbeitgeber jedoch zum Beispiel seine Sekretärin, die normalerweise den ganzen Tag sitzend arbeitet, trotz einer Knieverletzung ständig im Café oder beim Einkaufen, kann dies den Beweiswert der Arbeitsunfähigkeits- bescheinigung erschüttern. Die Sekretärin riskiert dann die Entgeltfortzahlung. Kann der Arbeitgeber beweisen, dass sie ihre Arbeitsunfähigkeit vortäuscht und/oder sie sich die Arbeitsunfähigkeitsbescheinigung erschlichen hat, indem sie ihre Tätigkeiten gegenüber dem Arzt falsch dargestellt hat, kann er das Arbeitsverhältnis kündigen. In der Regel schätzen Ärzte die Arbeitsunfähigkeit jedoch richtig ein, sodass diese Konsequenzen selten vorkommen. Karsten Bossow

\section{$\Rightarrow$ Wirft auch Ihr Berufsalltag rechtliche Fragen auf? Dann schreiben Sie an Simone.Gritsch@thieme.de.}

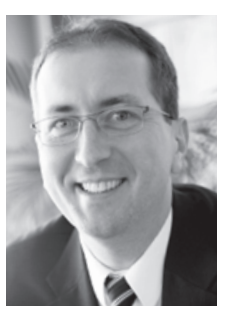

Karsten Bossow ist seit 1999 Rechtsanwalt mit den Tätigkeitsschwerpunkten Arbeits-, Medizin- und Sozialrecht. Seit 2003 ist er Fachanwalt für Arbeitsrecht und seit 2010 Fachanwalt für Medizinrecht. 